\title{
Н.В. Гагарина
}

Российский государственный педагогический университет, Санкт-Петербург

\section{К вопросу о принципах анализа грамматических категорий и глагольных форм в детской речи}

Аннотация: Исследование рассматривает принципы анализа глагольных форм и грамматических категорий в детской речи и предлагает набор жестких и мягких критериев для определения уровня «конвенциональности» детских глагольных форм и для их сопоставления с глагольными формами нормативного языка.

The study deals with the development of finite forms and grammatical categories in child Russian. Two groups of criteria, the stricter and the weaker, are proposed for the evaluation of the 'conventionality' level of children's finite forms and for the comparison of these forms with the input.

Ключевые слова: онтогенез, детская речь, глагольные формы, грамматические категории.

Дети начинают произносить первые осмысленные слова примерно в одиннадцать/двенадцать месяцев и уже примерно к трем/трем с половиной годам можно констатировать усвоение в целом основ грамматической системы родного языка. Появление в детской речи глагола - обычно это происходит через несколько месящев после употребления первых слов, обозначающих предметы окружающего мира, - дает толчок к развитию всей грамматической системы, к усложнению синтаксической структуры высказывания. Такая решающая роль глагола в развитии детской грамматики связана с его центральной ролью в предложении. Эта центральная, смыслообразующая роль глагола в предложении отмечалась еще в традиционных грамматиках (примечательно, что Аристотель различает только имя существительное и глагол). Л. Теньер [Tesnière, 1959] сравнивает «глагольный узел» большинства европейских языков с маленькой драмой, где глагол является сюжетом, глагольные аргументы играют роль главных героев, а оставшиеся члены предложения, такие, как обстоятельства, приложения и т.д., дополняют основную повествовательную линию дополнительной информацией. У. Чейф [Chafe, 1970, p. 97-98], имея в виду ведущую роль глагола в высказывании, предлагает другое сравнение, где глагол выполняет функцию солнца; все, что происходит с солнцем, влияет на всю солнечную систему, в целом, и на планеты, в частности ${ }^{1}$. Наконец, Н.Ю. Шведова, рассматривая характеристики глагола в плоскости лексической системы русского языка, отмечает ведущую «роль глагола как доминанты в системе лексических классов слов» [Шведова, 1995, с. 414].

Что касается решающей роли глагола в усвоении грамматики родного языка, то она была отмечена еще в первых дневниковых записях супругами Штерн в начале прошлого века [Stern and Stern, 1907], в период систематических лонги-

\footnotetext{
${ }^{1}$ Некоторые исследователи оспаривают решающую роль глагола в усвоении родного языка, см.: [Gentner, 1982; Gentner and France, 1988].
} 
тюдных и экспериментальных исследований семидесятых годов прошлого века [например, Bloom, Lifter and Hafitz 1980; Bloom, 1991] и в новейших работах нынешнего тысячелетия [например, Цейтлин 2000; Tomasello, 2003; Ingram, Welti and Priem 2006]. Автор данного исследования также считает, что глагол играет определяющую роль в развитии грамматической системы русского языка. Если данная позиция является верной, то нам представляется, что описание механизмов развития грамматических категорий глагола и периодизация их (категорий) становления могут служить базой для развития всей грамматической системы в целом. Дополнительным аргументом в пользу такой позиции может служить и замечание В.В. Виноградова о том, что «глагол - самая сложная и самая емкая грамматическая категория русского языка» [Виноградов, 1972, с. 337]. Анализ глагола как части речи и определение степени усвоения его грамматических характеристик, следовательно, может является своеобразной точкой omсчета для общего рассмотрения всей речевой системы ребенка.

Говоря о так называемом нормативном овладении одним языком, мы имеем в виду следующее: ребенок осваивает родной язык в естественных условиях, находясь в окружении взрослых-монолингвов, носителей того же языка, который предстоит усвоить ребенку. Воспринимая речь окружающих, обращенную к нему, так называемый инпут, и общаясь с окружающими, каждый ребенок самостоятельно конструирует грамматику родного языка. Учитывая решающую роль глагола при конструировании грамматической системы родного языка, необходимо определить основные принципы описания глагольных форм и их значений, выработать критерии анализа значений, выраженных этими глагольными формами. Принципы овладения не только формальным выражением, но и языковым содержанием языковых категорий глагола (с учетом инпута, получаемого ребенком), а также критерии описания глагольных форм в детской речи, несмотря на интенсивные исследования глагольных форм в онтолингвистике в последние десятилетия ${ }^{1}$, еще не нашли комплексного описания.

Интенсивные исследования по онтогенезу грамматических категорий глагола с акцентом на вид и время в русском языке начались сравнительно недавно (ссылки на современные работы см. ниже), если не принимать во внимание известную работу А.Н. Гвоздева, опубликованную еще в 1949 году [Гвоздев, 1949]. Отечественные исследования последних лет характеризуются функциональным и конструктивистским подходом к описанию и анализу фактов онтогенеза (см., например, [Пупынин, 1996, 1998; Князев, 1996, 2001; Цейтлин, 2000; Воейкова, 2001, 2007; Ахапкина, 2007; Сударева, 2007]). Результаты этих исследований не только не опровергли наблюдений А.Н. Гвоздева, но и подтвердили его обобщения на большом количестве материала. Внимание к семантическим разновидностям употребления видовременных форм, к детальному анализу речевого материала и контекстов употребления форм отличает исследования по детской речи, выполненные в русле теории функциональной грамматики Ход этих исследований показал необходимость анализа от содержания к форме, выявил основные закономерности усвоения вида и времени, заключающиеся в развитии от обозначения конкретных, единичных действий, соотнесенных с моментом речи, к осознанию и вербализации более обобщенных, не локализованных во времени действий.

Работы по анализу усвоения категорий глагола в русском языке характеризуются не только существенно большим единообразием в смысле результатов анализа различных данных (лонгитюдные и дневниковые записи, отдельные вы-

${ }^{1}$ Детальная разработка онтогенеза категорий вида и времени на материале русского языка проводилась Ю.А. Пупыниным, Ю.П. Князевым, Я. Э. Ахапкиной и др. 
сказывания $)^{1}$, но и большей ясностью толкований онтогенетических процессов в детской речи (см.: [Цейтлин, 1989; Князев, 1996; Пупынин 1996, 1998; Гагарина, 1997; Kiebzak-Mandera, Smoczyńska and Protassova, 1997Kiebzak-Mandera, 2000;] по сравнению с зарубежными работами. Единодушно отмечается постепенное усвоение частных значений совершенного и несовершенного видов и тенденция - особенно на ранних этапах онтогенеза - к употреблению глаголов СВ в прошедшем времени и глаголов НСВ в настоящем времени. Также отмечается ситуативность детской речи и тесная связь содержания высказывания с конкретной внеязыковой ситуацией [Князев, 2000], однако конкретно описанных критериев анализа глагольных форм и их значений, «инструментария» для определения «конвенциональности» формы на основе ее значений и минимального набора/количества форм для определения усвоения выражаемых ими категорий (в детской речи) пока еще не было предложено.

Теоретическая основа данного исследования реализуется в концепции Петербургской школы функциональной грамматики (см. труды Ю.С. Маслова, А.В. Бондарко, серии коллективных монографий [ТФГ, 1987; 1990; 1991; 1992; 1996], а также [ПФГ, 2000; 2003; 2005]). В основе теории функциональной грамматики лежит принцип рассмотрения языковых явлений преимущественно от смысла к способам его выражения, применяемый к анализу грамматических категорий в детской речи.

Объект анализа в нашей работе - предложения, имеющие в своем составе знаменательный или вспомогательный глагол и не повторенные непосредственно за взрослым. На ранних этапах онтогенеза высказывания содержат только один компонент, например: Cnamb (Ваня в 2;012 прыгает по комнате, потом забирается на маму и ползает по ней, говоря: Cnamb, через некоторое время: Дождь; мама соглашается с ребенком: Да, дождь, спать пора) или Мышонок cnum (Лиза в 2;00 укладывает мышонка на спину черепахи и комментирует). Позже предложения, конструируемые ребенком, становятся многокомпонентными: У кошки лапка болит тоже (Ваня 2;03) или Бабушка вот здесь сидит (Ваня 2;03). Основным материалом работы послужили спонтанные лонгитюдные записи речи четырех детей - Лизы, Вани, Ромы ${ }^{3}$ и Вити. Лиза - второй ребенок (ее брат на десять лет старше) в семье филологов, и записи ее спонтанной речи дополнены тщательно ведущимися дневниковыми записями. Речь всех детей более или менее систематически записывалась на видео- и аудионосители от двух до пяти раз в месяц (средняя продолжительность записей речи одного ребенка в месяц составляет примерно 180 минут). Детская речь и почти весь инпут затранскрибирован и закодирован ${ }^{4}$ в системе CHILDES [MacWhinney, 2000] с помощью морфологического кодировщика MORCOMM [Voeikova, 2000; Gagarina, Voeikova and Gruzincev, 2002].

Уже в самом начале записей встречаются глагольные формы, напоминающие конвенциональные, см. примеры выше. При анализе таких форм применяется терминологический аппарат нормативной грамматики: так, например, сnит является формой несовершеного вида настоящего времени 3-го лица единственного числа. Означает ли наличие данной формы в детской речи и наличие (всего

\footnotetext{
${ }^{1}$ Современный взгляд на ход онтогенетического развития вида и времени в русском языке также не противоречит результатам исследования А.Н. Гвоздева [1949] полувековой давности.

${ }^{2}$ Возраст ребенка на момент записи два года. Возраст ребенка указывается следующим образом: год; месяц.

${ }^{3}$ Информация о данных Ромы отсутствует в разделе приложение, его записи были прерваны на три месяца после 2;1.

4 Огромную благодарность за титанический труд по транскрибированию и кодированию данных приносим М.И. Аккузиной и Е.К. Лимбах.
} 
спектра) значений, присущих данной форме в нормативном языке? На ранних этапах онтогенеза мы не можем еще говорить о конвенциональных значениях и о системе грамматических форм, выражающих определенное значение, не можем еще говорить о грамматической категории как таковой, тем не менее мы используем этот термин, имея в виду некую аморфную протокатегорию, некий ее эмбрион, из которого впоследствии разовьется соответствующая нормативная категория. Этот эмбрион грамматической категории чаще всего представляет только одну какую-либо часть содержания нормативной грамматической категории; содержания, которое становится очевидным из подробных комментариев к речевой продукции детей и анализа речи собеседников детей вместе с интересующей нас словоформой.

Для описания первых глаголов, их отдельных форм и (продуктивных) систем оппозиций спрягаемых форм глаголов мы предлагаем несколько критериев анализа. Первым критерием является формальное, то есть звуковое, соответствие нормативному глаголу (с учетом слоговой элизии, упрощения кластеров и т.д.). Далее, для описания грамматических категорий необходимо наличие их формального выражения материальными звукокомплексами в словоформах. В этих словоформах, напоминающих нормативные, должна отчетливо обнаруживаться маркированность данной категории. Несмотря на то, что наличие какойлибо одной глагольной формы или аффикса не дает нам еще возможности говорить о категории или даже о ее предшественнике, анализ таких отдельных форм чрезвычайно важен, так как накопление этих форм ведет к их организации в систему, из которой впоследствии возникают грамматические категории.

Вторым критерием анализа грамматических категорий является появление противопоставленных форм. Подчеркнем еще раз, наличие в речи ребенка, например, формы 3-го лица единственного числа какого-либо глагола, не дает нам оснований для утверждения о том, что мы имеем дело с грамматической категорий лица или числа. Напротив, только наличие нескольких контрастных спрягаемых форм, в которых, при тождестве одной категории (в нашем примере (1) лицо), изменяется другая категория (в нашем примере (1) - число), дает нам основание говорить о начале процесса становления категории числа, о начале усвоения ребенком формального обозначения этой категории в (системе) личных глагольных форм русского языка. При этом содержание категории может уже проявляться на более ранних этапах, до того времени, как возникло ее нормативное оформление. Это содержание может быть выражено лексическими средствами. Характерен в этом случае глагольный вид, когда дети, не имея еще в своем арсенале собственно глагольных форм, по-разному используют ономатопеи для обозначения длящихся и законченных действий (подробнее об этом см.: [Гагарина 1997]).

(1) \%ситуация: Ваня $(2 ; 02)$ играет с машинкой

*ВАН: ${ }^{1}$ Горит, щёлк горит.

*БАБ: Ваня так включает фары, щелк, горит.

*BAH: Горит@errv² фары.

*БАБ: Ваня, а что эта машина возит?

*БАБ: Кого она возит?

*ВАН: Людей.

\footnotetext{
${ }^{1}$ Сокращение ВАН обозначает реплики Вани, сокращение БАБ обозначает реплики бабушки.

2 @errv означает ошибку в употреблении формы глагола. В данной работе мы опускаем особенности произношения Вани и приводим конвенциональный вариант произношения.
} 
*БАБ: Людей, правильно.

\% ситуация: Ваня наезжает машинкой на бабушку.

*BАН: Бабу.

*БАБ: Задавила бабушку машина?

*BAН: Да.

*БАБ: Так нельзя делать, машина не должна никого давить.

*BAН: Стоит.

*BAН: горят фары нет.

*БАБ: Не горят фары.

Далее, возникновение рядов противопоставленных форм, их накопление и объединение в систему является решающим шагом в усвоении формального выражения анализируемых категорий. При этом, однако, необходимо учитывать количественные и качественные показатели рядов форм, такие как частотность употребления, соотношение с другими частями речи, контексты употреблений, синтаксическую структуру предложения и общий уровень развития грамматической системы (уместнее было бы говорить о навыках использования грамматических правил) и т.д. Рассмотрим пример из речи Ромы, который в 1;11 употребил три формы прошедшего времени упал (зафиксировано 12 раз), упала (6 раз) и упали (1 раз). Казалось бы, мы имеем дело с противопоставлениями <мужской род - женский род> и <множественное число - единственное число $>$ и, следовательно, должны анализировать данные формы, как первичное обозначение соответствующих категорий. Внимательный анализ контекстов употреблений и рассмотрение структурных особенностей основы этих форм (примеры (2) - (4)) не дают нам оснований для такой интерпретации:

(2) \%сит: игрушечное колесо падает из Роминых рук, и он комментирует *РОМ: $\quad$ ххх упал.

(3) \%сит: Рома бросает пластмассовую бутылочку и наблюдает, как она катится

*РОМ: Упал

(4) \%сит: Рома подходит к креслу, берет лежащую на нем накидку и бросает ее на пол, комментируя

*POM: Упали.

1) в предложениях отсутствует подлежащее, и из комментариев к ситуации следует неверное согласование сказуемого с субъектом действия (подлежащим);

2) при анализе всей речевой продукции в это время мы не наблюдаем признаков различения рода и числа;

3) спрягаемые формы образованы только от одного типа основы - открытой основы инфинитива;

4) в записях речи не встречается никаких других глаголов в форме прошедшего времени;

5) отсутствуют противопоставления данного глагола по виду. Вышеприведенные аргументы кажутся нам достаточными для того, чтобы обозначить анализируемый процесс как формовоспроизводство, а не формопроизводство. Следовательно, мы также не можем говорить о наличии - и даже возникновении грамматических категорий числа и рода в данном случае. Ребенок передает лишь самый базовый смысл ситуации падения, используя при этом такую глагольную форму, которая находится в его распоряжении и которую он чаще всего слышал в инпуте (глагол передает правильное мыслительное, событийное содержание 
при отсутствии конвенционального грамматического значения, требуемого в данном контексте).

Рассмотрим еще один пример из речи Ромы в 2;00: два глагола НСВ употреблены в формах инфинитива и 3-го лица единственного числа пuть и nьem, cnamb и сnum. Несмотря на то, что в данном примере наблюдается использование двух основ (открытой и закрытой), и ребенок употребляет глаголы контекстуально правильно, мы не можем считать данные формы произведенными на основе извлеченных из инпута и генерированных ребенком правил. Так, глагольный лексикон Ромы в это время состоит из восьми глаголов, общий уровень развития грамматической системы довольно низок, отсутствует достаточное количество рядов противопоставленных форм других глаголов, высказывания с этими глаголами не содержат подлежащего. Следовательно, мы не можем говорить не только об усвоении форм 3-го лица, но даже и о возникновении продуктивного использования этих форм. Таковы жесткие критерии для описания грамматических категорий. Набор мягких критериев может включать в себя анализ только спрягаемой формы и/или ряда форм (неорганизованного пучка форм) без учета факторов, определяющих общий уровень грамматической системы и наличия аналогичных спрягаемых форм группы лексем.

Представим особенности усвоения, например, форм лица в виде схемы:

\section{Схема 1}

\begin{tabular}{|c|c|}
\hline Описание примеров употребления & $\begin{array}{c}\text { Схематическое представление } \\
\text { примеров } \\
\text { употребления }\end{array}$ \\
\hline $\begin{array}{l}\text { (I) Глагол А употреблен в фор- } \\
\text { ме 1-го лица; глагол Б употреблен в } \\
\text { форме 1-го лица; глагол В употреб- } \\
\text { лен в форме 1-го лица; глагол } n \\
\text { употреблен в форме 1-го лица; <..> }\end{array}$ & 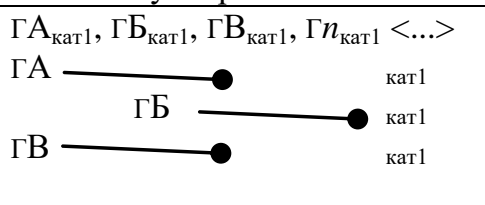 \\
\hline $\begin{array}{l}\text { (II) Глагол А употреблен в фор- } \\
\text { ме 1-го лица ед. ч.; глагол А упот- } \\
\text { реблен в форме 2-го лица ед. ч.; гла- } \\
\text { гол А употреблен в форме } 3 \text {-го лица } \\
\text { ед. ч. <..> }\end{array}$ & 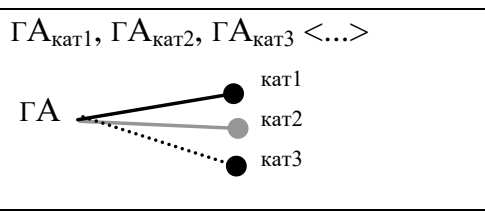 \\
\hline $\begin{array}{l}\text { (III) Глагол А употреблен в } \\
\text { форме 1-го лица ед. ч.; глагол А } \\
\text { употреблен в форме 2-го лица ед. ч.; } \\
\text { глагол А употреблен в форме } 3 \text {-го } \\
\text { лица ед. ч. <... }>\text {, глагол Б употреблен } \\
\text { в форме 1-го лица ед. ч.; глагол Б } \\
\text { употреблен в форме 2-го лица ед. ч.; } \\
\text { глагол Б употреблен в форме } 3 \text {-го } \\
\text { лица ед. ч. <...>, глагол } n \text { употреблен } \\
\text { в форме 1-го лица ед. ч.; глагол } n \\
\text { употреблен в форме 2-го лица ед. ч.; } \\
\text { глагол } n \text { употреблен в форме } 3 \text {-го } \\
\text { лица ед. ч. <...> }\end{array}$ & 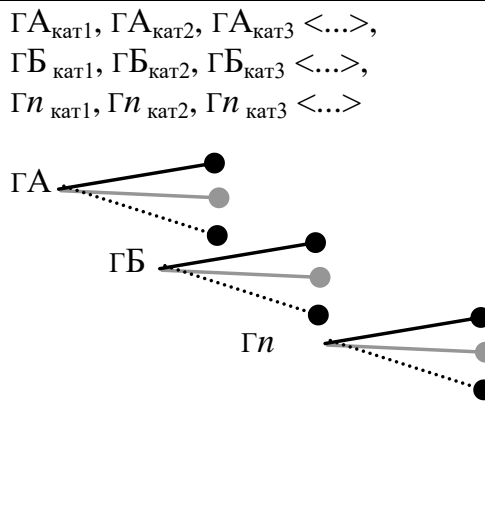 \\
\hline
\end{tabular}

Факт наличия в детской речи ступеней (I) и (II) анализируется нами как подготовительный этап в усвоении категории лица. Его можно сравнить с лексическим взрывом, который считается предвестником усвоения грамматических 
форм определенной части речи. Считается, что для того чтобы дети могли начать усвоение какой-либо глагольной грамматической категории, в их лексиконе должно содержаться определенное количество глаголов. В самом начале происходит накопление лексических единиц - чаще всего посредством так называемого лексичского взрыва ${ }^{1}$, а потом - накопление и организация форм.

Аналогичным образом, как нам кажется, инфлектикон (набор спрягаемых форм, термин С.Н. Цейтлин по аналогии с термином Ю.Н. Караулова грамматикон) должен содержать достаточное количество форм, чтобы можно было говорить о начале усвоения этих форм, представляющих данную категорию. Накопление спрягаемых форм 1-го лица единственного числа с различными глаголами; употребление одной и той же глагольной лексемы в форме как 1-го лица, так и 3-го лица; возрастающее количество рядов противопоставленных форм все большего числа глаголов; объединение этих форм в упорядоченную систему является процессом усвоения грамматической категории лица. Аналогичная схема может быть построена для категорий вида и времени с оговоркой, что при анализе усвоения этих категорий особое внимание должно быть уделено семантическим различиям, которые не получили отражения в таблице. Учет возникновения различных типов значений форм, которые также постепенно организуются в систему, является определяющим для рассмотрения развития этих категорий. Критериями объединения рядов форм в упорядоченную систему и выстраиванием парадигматических отношений могут служить количественные и качественные характеристики этих форм и их значений, определяющие уровень соответствия детской языковой системы той конвенциональной грамматической системе, которую постигает ребенок.

В заключение отметим, что данное исследование рассматривает принципы анализа грамматических категорий и глагольных форм в детской речи и предлагает набор жестких и мягких критериев для определения уровня «конвенциональности» детских глагольных форм и для их сопоставления с глагольными формами нормативного языка.

\section{Литература}

Ахапкина Я.Э. Типы временной локализованности на раннем этапе речевого онтогенеза // Семантические категории в детской речи. СПб., 2007.

Воейкова М.Д. Формальные особенности парадигмы прилагательного и ее усвоение детьми // Речь ребенка: ранние этапы. Труды постоянно действующего семинара по онтолингвистике. СПб., 2001.

Воейкова М.Д. Усвоение детьми категории количественности // Семантические категории в детской речи. СПб., 2007.

Виноградов В.В. Русский язык: грамматическое учение о слове. М., 1972.

Гагарина Н.В. Аспектуальная семантика и функционирование видов русского глагола в детской речи: Дис. ... канд. филол. наук, СПб., 1997.

Гвоздев А.Н. Формирование у ребенка грамматического строя русского языка. М., 1949.

Князев Ю.П. Стратификация видо-временных значений и детская речь // Материалы международного симпозиума «Сто лет Р.О. Якобсону». М., 1996.

Князев Ю.П. Основные этапы усвоения видо-временных значений в детской речи // Речь ребенка: первые этапы. СПб., 2000.

\footnotetext{
${ }^{1}$ Более подробно о дебатах по поводу лексического взрыва (lexical spurt) cм. [Goldfield and Reznick, 1990; Anglin, 1993; Clark, 1993; Mervis and Bertrand, 1995; Rescorla, Mirak and Singh, 2000; Bloom, 2002].
} 
Князев Ю.П. Формирование видо-временных противопоставлений в детской речи // Исследования по языкознанию: К 70-летию чл.-корр. РАН А.В. Бондарко. СПб., 2001.

Пупынин Ю.А. Усвоение системы русских глагольных форм (ранние этапы) // Вопросы языкознания. 1996. № 3.

Пупынин Ю.А. Элементы видо-временной системы в детской речи // Вопросы языкознания. 1998. № 2.

Проблемы функциональной грамматики: Категории морфологии и синтаксиса высказывания. СПб., 2000. (ПФГ)

Проблемы функциональной грамматики: Семантическая инвариантность/вариативность. СПб., 2003.

Проблемы функциональной грамматики: Полевые структуры. СПб., 2005.

Сударева О. Г. Ранние этапы освоения детьми временных отношений и способов их языкового выражения // Семантические категории в детской речи. СПб., 2007.

Теория функциональной грамматики: Введение. Аспектуальность. Временная локализованность. Таксис. Л., 1987. (ТФГ) 1990.

Теория функциональной грамматики: Темпоральность. Модальность. Л., 1991.

Теория функциональной грамматики: Персональность. Залоговость. СПб.,

Теория функциональной грамматики: Субъектность. Объектность. Коммуникативная перспектива высказывания. Определенность/ неопределенность. СПб., 1992.

Цейтлин С.Н. Детская речь: инновации формообразования и словообразования (на материале современного русского языка): Дис. ... докт. филол. наук. Л., 1989.

Цейтлин С.Н. Язык и ребенок. Лингвистика детской речи. М., 2000.

Шведова Н.Ю. Глагол как доминанта в системе русской лексики // Филологический сборник. (К 100-летию со дня рождения академика В.В. Виноградова). M., 1995.

Anglin J. Vocabulary development // Monographs of the Society for Research in Child Development. 1993. N 10.

Bloom L. Language Development: From Two To Three. Cambridge, 1991.

Bloom L., Lifter K., Hafitz J. Semantics of the verbs and the development of verb inflection in child language // Language. 1980. N 56.

Bloom P. How children learn the meanings of words. Cambridge, 2002.

Chafe W.L. Meaning and the structure of Language. Chicago, 1970.

Clark E.V. The Lexicon in Acquisition. Cambridge, 1993.

Gagarina N., Voeikova M. and Gruzincev S. New version of morphological coding for the speech production of Russian children (in the framework of CHILDES) // Investigations info Formal Slavic Linguistics. Peter Lang, 2002.

Gentner D. Why nouns are learned before verbs: Linguistic relativity versus natural partitioning // Language development. Hillsdale NJ, 1982.

Gentner D., France I.M.. The verb mutability effect: studies of the combinatorial semantics of nouns and verbs // Lexical ambiguity resolution: perspectives from psycholinguistics, neurepsychology, and artificial intelligence. San Mateo, 1988.

Goldfield B., Reznick S. Early Lexical Acquisition: Rate, Content, and the Vocabulary Spurt // Journal of Child Language. 1990. N 17.

Ingram D., Welti A., Priem C. The early stages of verb acquisition in Spanish, German and English // The acquisition of verbs and their grammar: the effect of particular languages. Springer, 2006.

Kiebzak-Mandera D. Formation of the verb system in Russian children // Psychology of Language and Communication. 2000. N 4. 
Kiebzak-Mandera D., Smoczyńska M., Protassova E. Acquisition of Russian verb morphology: The early stages // Studies in Pre- and Protomorphology. Wien, 1997.

Mervis C., Bertrand J. Early Lexical Acquisition and the Vocabulary Spurt: A Response to Goldfield and Reznick // Journal of Child Language. 1995. N 22.

Rescorla L., Mirak J., Singh L. Vocabulary growth in late talkers: lexical development from 2;0 to 3;0 // Journal of Child Language. 2000. N 27.

Stern C., Stern W. Die Kindersprache. Leipzig, 1907.

Tesnière L. Éleménts de syntaxe structurale. Paris, 1959.

Tomasello M. Constructing a Language. Cambridge, 2003.

Voeikova M. Russian existential sentences: A functional approach. München, 2000 . 